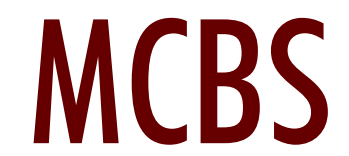

Mol Cell Biomed Sci. 2021; 5(1): 18-21

DOI: $10.21705 / \mathrm{mcbs} . v 5 i 1.177$

\title{
The Effect of Carnitine Supplementation on Blood Ammonia Level in Epilepsy Children Treated with Valproic Acid: A Randomized Controlled Trial
}

\author{
I Gusti Lanang Sidiartha ${ }^{1}$, I Gusti Ngurah Made Suwarba², Dyah Kanya Wati ${ }^{3}$, Ida Bagus Subanada ${ }^{4}$ \\ ${ }^{1}$ Pediatric Nutrition and Metabolic Disease Division, Department of Child Health, Faculty of Medicine, Universitas Udayanal \\ Sanglah General Hospital, Denpasar, Bali, Indonesia \\ ${ }^{2}$ Pediatric Neurologic Division, Department of Child Health, Faculty of Medicine, Universitas Udayana/Sanglah General Hospital, \\ Denpasar, Bali, Indonesia \\ ${ }^{3}$ Pediatric Intensive Care Division, Department of Child Health, Faculty of Medicine, Universitas Udayana/Sanglah General \\ Hospital, Denpasar, Bali, Indonesia \\ ${ }^{4}$ Pediatric Respirology Division, Department of Child Health, Faculty of Medicine, Universitas Udayana/Sanglah General \\ Hospital, Denpasar, Bali, Indonesia
}

Background: Long-term use of valproic acid is associated with a high level of blood ammonia related to carnitine deficiency. This study investigates the effect of carnitine supplementation on blood ammonia levels in children with epilepsy who have been treated with valproic acid for more than six months.

Materials and Methods: This was a randomized, double-blind, placebo-controlled trial study where children with epilepsy who were treated with valproic acid were randomly allocated to the carnitine supplementation and control group. All children were followed for month, and then measured for blood ammonia level. Blood ammonia levels of both groups were compared using an Independent t-test with a significant of $p<0.05$.

Results: Total of 32 children with epilepsy were enrolled as subjects in this study, with 16 children in carnitine group, and 16 children in control group. Among the subjects, $50 \%$ were male and $50 \%$ were female, with a mean age of 6.5 years old. The average duration of epilepsy in the carnitine and control group were 41.7 months and 36.9 months, respectively $(p=0.419)$. The duration of valproic acid therapy in the carnitine and control group were 33.1 months and 27.6 months, respectively $(p=0.483)$. The level of blood ammonia in carnitine and control group were $44.6 \mu \mathrm{g} / \mathrm{dL}$ and $81.4 \mu \mathrm{g} / \mathrm{dL}$, respectively ( $p=0.007)$.

Conclusion: The level of blood ammonia in a carnitine group was significantly lower than in a control group. It is recommended to give carnitine supplementation in epileptic children treating with long-term valproic acid.

Keywords: ammonia, carnitine, epilepsy, seizure, valproic acid 


\section{Introduction}

Valproic acid is widely used in children or adults with epilepsy. This drug is very effective to control seizures in epileptic children and commonly used for a long time. ${ }^{1,2}$ The long-term used of valproic acid is associated with the increase of a serum ammonia level. ${ }^{3}$ Ammonia is toxic and causes central nervous system damaged. ${ }^{4}$ This condition should be prevented by the doctors who are treating the children with epilepsy.

Valproic acid is a short-chain fatty acid that is found for the first time in 1882 and then reported having an antiepileptic agent in $1962 .{ }^{1}$ Until now, valproic acid is used as the first choice of anti-epileptic drug in childhood epilepsy. ${ }^{1}$ Valproic acid is used in controlling seizure as a single or combined drug in children with epilepsy. The mechanism of valproic acid in controlling seizure is by inhibiting the degradation of neurotransmitter gamma-aminobutyric acid.

The long-term used of valproic acid is associated with many side effects such as fatigue, intestinal discomfort, increased body weight, tremor, hair loss, thrombocytopenia, increased liver enzyme, and increased blood ammonia. ${ }^{5-8}$ The increased blood ammonia is a serious side effect of long-term used of valproic acid. It is associated with the liver and central nervous system damaged. The increased blood ammonia was reported to vary between $27.8 \%$ to $67.7 \%$.,5,9

The high blood ammonia level related to the long-term used of valproic acid is associated with the inhibition of enzyme carbamoyl phosphate synthetase-1 and pressing the availability of acetyl-coenzyme-A that causing carnitine deficiency. ${ }^{10}$ Both of this mechanism causes the impairment of the urea cycle resulting in the accumulation of blood ammonia. The increased of blood ammonia is also caused by the disease of inborn error of metabolism, acute or chronic liver disease, acute or chronic kidney disease, Reye syndrome and using drugs 5 -fluorouracil and salicylate. ${ }^{10}$

Carnitine supplementation has been reported decreasing the blood ammonia level related valproic acid therapy for several years ago. ${ }^{11-14}$ Previously studies reported the effectiveness of carnitine supplementation in the valproic acid intoxication and psychiatric setting. However, along with our knowledge, there is no data on the effect of carnitine supplementation in epilepsy children related to valproic acid therapy. This study investigates the blood ammonia level of epileptic children treated with valproic acid for more than six months and compare its level between children who received carnitine and without carnitine supplementation.

\section{Materials and methods}

\section{Study Design}

The current study was a randomized, double-blind, placebocontrolled trial conducted between September and December 2018 at Pediatric Ward, Sanglah General Hospital, Denpasar, Bali, Indonesia. The study was approved by The Ethical Committee of the Medical Faculty, Udayana University, Sanglah General Hospital, Denpasar, Bali, Indonesia (No. 2361/UN14.2.2.VII.14/LP/2018).

\section{Study Populations and Randomization}

The study included children aged 1-18 years old who were diagnosed as epilepsy and have been treated with valproic acid for more than six months. The subjects were excluded if they suffered from the urea cycle disease, received the drugs that influenced the blood ammonia level, such as salicylate, anti-human immunodeficiency virus (HIV), and chemotherapy, and suffered from the liver and the kidney function impairment.

Subjects who met the inclusion and exclusion criteria were randomly allocated to the supplementation and control group. The random allocation was determined using a computer system with a block size of four. Both subjects and study investigators did not know the group allocation. The supplementation group received $500 \mathrm{mg}$ carnitine capsule twice a day for 30 days. The control group received a similar capsule contain saccharin lactis twice a day for 30 days.

Among 45 subjects who were eligible as a sample, 7 subjects did not met the inclusion criteria because they received valproic therapy for less than 6 months. A total of 38 subjects were randomly allocated, with 19 subjects in each group. On the follow-up, 6 subjects dropped out. In the end, 32 subejcts completed the study, with 16 subhects in each group.

\section{Data Collection}

Data regarding age, gender, body mass index (BMI), duration of epilepsy, duration of valproic acid therapy, serum glutamic pyruvic transaminase (SGPT), serum glutamic oxaloacetic transaminase (SGOT), blood urea nitrogen (BUN), and serum creatinine (SC) were collected 
at the beginning of the study. The children were followed and monitored for the side effects during the study period. In the end, the blood ammonia level was measured in both groups. Blood ammonia was measured using enzymatic glutamate dehydrogenase in Quantum Laboratory, Denpasar, Bali.

\section{Statistical Analysis}

The minimal sample size was 16 subjects each group according to the power $80 \% \quad(Z \beta=0.842), \quad \alpha=0.05$ $(\mathrm{Z} \alpha=1.96)$. The independent t-test was done to analyzed the differences between the blood ammonia level between group. The significant level was considered if $p$-value $<0.05$. All analysis was performed using SPSS software (IBM Coorporation, Armonk, NY, USA) version 20.0.

\section{Results}

A total of 32 children completed the study, 16 males and 16 females, respectively. The mean aged of children in the supplementation and control group was $83.9 \pm 35.5$ months and $72.2 \pm 40.6$ months, respectively (Table 1). The study characteristics, such as gender, age, BMI, duration of epilepsy, duration of valproic acid therapy, SGPT, SGPT, BUN, and SC were not statistically different between groups $(p>0.05)$. On the other hand, the blood ammonia level between groups at the end of the study was statistically significant with $p$-value $=0.007$ (Table 2).

\section{Discussion}

This study found that the children with epilepsy who were treated with valproic acid and received carnitine supplementation tend to have lower blood ammonia levels compared with the children without carnitine supplementation. The blood ammonia level in the carnitine supplementation group and the control group was 44.6 $\mu \mathrm{g} / \mathrm{dL}$ and $81.4 \mu \mathrm{g} / \mathrm{dL}$, respectively. It was the $45.2 \%$ lower of the blood ammonia level in the carnitine group than the control group. The result is essential and is recommended to be implemented. It could be suggested to give carnitine supplementation in children with epilepsy who have been treated with long-term valproic acid in controlling seizure.

Along with our knowledge, the current study is the first study investigating the effectiveness of carnitine supplementation on blood ammonia in children with epilepsy. Other studies on different settings reported similar results. A study on psychiatric settings reported that the carnitine supplementation doses of $30 \mathrm{mg} / \mathrm{kg} /$ day during 3 months reduced blood ammonia level from $108.3 \mu \mathrm{g} / \mathrm{dL}$ to $93.1 \mu \mathrm{g} / \mathrm{dL} .{ }^{11}$ Unfortunately, this result was not statistically significant. Study in an adult with valproic acid intoxication (plasma level $>100 \mu \mathrm{g} / \mathrm{mL}$ ) reported that carnitine supplementation with doses of $1800 \mathrm{mg} /$ day reduced the blood ammonia from $264 \mu \mathrm{mol} / \mathrm{dL}$ to $64.1 \mu \mathrm{mol} / \mathrm{dL}$ within 72 hours. $^{12}$ They concluded that carnitine supplementation

Table 1. The general characteristic of children.

\begin{tabular}{|c|c|c|c|}
\hline Characteristic & $\begin{array}{l}\text { Supplementation Group } \\
\qquad(\mathrm{n}=16)\end{array}$ & $\begin{array}{c}\text { Control Group } \\
(n=16)\end{array}$ & $p$-value \\
\hline Gender, male/female & $8 / 8$ & $8 / 8$ & 0.638 \\
\hline Age (mo.), mean + SD & $83.9 \pm 35.5$ & $72.2 \pm 40.6$ & 0.394 \\
\hline $\mathrm{BMI}\left(\mathrm{kg} / \mathrm{m}^{2}\right)$, mean $+\mathrm{SD}$ & $17.2 \pm 3.1$ & $16.2 \pm 3.7$ & 0.402 \\
\hline Duration of epilepsy (mo.), mean \pm SD & $41.7 \pm 31.3$ & $36.9 \pm 24.9$ & 0.419 \\
\hline Duration of VPA (mo.), mean \pm SD & $33.1 \pm 24.1$ & $27.6 \pm 18.9$ & 0.483 \\
\hline $\operatorname{SGOT}(\mu / \mathrm{L})$, mean $+\mathrm{SD}$ & $27.1 \pm 2.2$ & $27.1 \pm 5.7$ & 0.960 \\
\hline $\operatorname{SGPT}(\mu / \mathrm{L})$, mean $+\mathrm{SD}$ & $16.1 \pm 5.2$ & $14.6 \pm 4.2$ & 0.403 \\
\hline $\mathrm{BUN}(\mathrm{mg} / \mathrm{dL})$, mean $+\mathrm{SD}$ & $21.3 \pm 3.1$ & $22.3 \pm 4.5$ & 0.499 \\
\hline $\mathrm{SC}(\mathrm{mg} / \mathrm{dL})$, mean $+\mathrm{SD}$ & $0.3 \pm 0.01$ & $0.3 \pm 0.07$ & 0.874 \\
\hline
\end{tabular}

BMI: body mass index; BUN: blood urea nitrogen; SC: serum creatinine; SD: standard deviation; SGOT: serum glutamic oxaloacetic transaminase; SGPT: serum glutamic pyruvic transaminase; VPA: valproic acid. 
Table 2. The blood ammonia level in the supplementation and the control group.

\begin{tabular}{ccccc}
\hline Variable & $\begin{array}{c}\text { Supplementation } \\
\text { Group }\end{array}$ & $\begin{array}{c}\text { Control } \\
\text { Group }\end{array}$ & $\begin{array}{c}\text { Mean Difference } \\
\text { (95\%CI) }\end{array}$ & $\boldsymbol{p}$-value \\
\hline Blood ammonia, $\mu \mathrm{g} / \mathrm{dL}$, mean (SD) & 44.6 & 81.4 & $36.8(11.1-62.7)$ & 0.007 \\
\hline
\end{tabular}

CI: confidence interval; SD: standard deviation.

was effective in reducing the blood ammonia and it could be used preventing encephalopathy related to valproic acid intoxication. ${ }^{12}$

L-carnitine has a potential capacity in treating metabolic encephalopathy caused by a high level of blood ammonia. ${ }^{13,14}$ In humans, ammonia is a product of protein and amino acid metabolism. Ammonia is a toxic substance, especially on the central nervous system and it should be degraded to urea through the urea cycle in the liver. The mechanism of the urea cycle in the liver needs several enzymes. In liver diseases, cells damaged and enzyme deficiency cause accumulation of blood ammonia resulting in hepatic hyperammonemia encephalopathy and death. Valproic acid intoxication also cause hyperammonemia encephalopathy that could be prevented with carnitine supplementation. ${ }^{10}$

The limitation of the study has not measured the level of the blood valproic acid, so it is difficult to consider that the high level of the blood ammonia associated with the high level of blood valproic acid. Another limitation was not measuring the level of the blood carnitine. It makes difficulty in measuring the increase of the blood ammonia level is caused by the decrease of the blood carnitine related to valproic acid therapy.

\section{Conclusion}

The study concludes that carnitine supplementation in children with epilepsy who were treated with long-term valproic acid was effective in lowering the blood ammonia level. It is recommended that epileptic children treating with long-term valproic acid should be added carnitine supplementation.

\section{Acknowledgments}

Many thanks to the subjects and their parents or caregivers for their participation in this study. We also thank the Quantum Laboratory staff for helping this study.

\section{References}

1. Ximenes JCM, Verde ECL, Naffah-Mazzacoratti MG, Viana GSB. Valproic acid, a drug with multiple molecular targets related to its potensial neuroprotective action. Neuroscience \& Medicine. 2012; 3(1): 107-23.

2. Trinka E, Hofler J, Zerbs A, Brigo F. Efficacy and safety of intravenous valproate for status epilepticus: a systematic review. CNS Dugs. 2014; 28(7): 623-39.

3. Vazquez M, Fagiolino P, Maldonado C, Olmos I, Ibarra M, Alvariza S, et al. Hyperammonemia associated with valproic acid concentrations. BioMed Res Int. 2014; 2014: 217269. doi: $10.1155 / 2014 / 217269$.

4. Tseng YL, Huang CR, Lin CH, Lu YT, Lu CH, Chen NC, et al. Risk factors of hyperammonemia in patients with epilepsy under valproic acid therapy. Medicine. 2014; 93(11): e66. doi: $10.1097 /$ MD.0000000000000066.

5. Tesen H, Katsuki A, Hori H, Atake K, Yoshimura R, Nakamura J. Plasma ammonia levels in patients treated with valproic acid. Neuropsychiatry. 2017; 7(1): 42-7.

6. Chang R, Chou MC, Hung LY, Wang ME, Hsu MC, Chiu CH. Study of valproic acid-enhanced hepatocyte steatosis. BioMed Res Int 2016; 2016: 9576503. doi: 10.1155/2016/9576503.

7. Nasreddine W, Beydoun A. Valproate-induced thrombocytopenia: a prospective monotherapy study. Epilepsia. 2008; 49(3): 438-45.

8. Agarwal R, Sharma S, Chhillar N, Bala K, Singh N, Tripathi CB. Hyperammonemia and hepatic status during valproate therapy. Indian J Clin Biochem. 2009; 24(4): 366-9.

9. Hung TY, Chen CC, Wang TL, Su CF, Wang RF. Transient hyperammonemia in seizures: a prospective study. Epilepsia, 2011; 52(11): 2043-9.

10. Segura-Bruna N, Rodriguez-Campello A, Puente V, Roquer J. Valproate-induced hyperammonemic encephalopathy. Acta Neurol Scand. 2006; 14(1): 1-7. doi: 10.1111/j.1600-0404.2006.00655.x.

11. Nakamura M, Nagamine $T$. The effect of carnitin supplementation on hyperammonemia and carnitine deficiency treated with valproic acid in a psychiatric setting. Innov Clin Neurosci. 2015; 12(9-10): $18-24$.

12. Maldonado C, Guevara N, Silveira A, Fagiolino P, Vazquez M. L-carnitine supplementation to reverse hyperammonemia in a patient undergoing chronic valproic acid treatment: A case report. I Int Med Res. 2017; 45(3): 1268-72.

13. Tincu RC, Cobilinschi C, Tomescu D, Coman L, Tincu I, Diaconu C, et al. Favourable results for L-Carnitine use in valproic acid acute poisoning. Farmacia. 2017; 65(3): 396-400.

14. Lheureux PER, Penaloza A, Zahir S, Gris M. Science review: carnitine in the treatment of valproic acid-induced toxicity - what is the evidence? Critical Care, 2005; 9(5): 431-40. 